Т а бл ица 4

Термодинамические свойства сплава Cr-Si при 2173 K

\begin{tabular}{c|c|c|c}
\hline$X_{\mathrm{Si}}$ & $a_{\mathrm{Cr}}$ & $a_{\mathrm{Si}}$ & $Q$, кДж/моль \\
\hline 0,1 & 0,866 & 0,00050 & 113 \\
0,2 & 0,657 & 0,00435 & 104 \\
0,3 & 0,439 & 0,0176 & 101 \\
0,4 & 0,266 & 0,0454 & 102 \\
0,5 & 0,132 & 0,105 & 105 \\
0,6 & 0,0435 & 0,256 & 105 \\
0,7 & 0,0115 & 0,492 & 105 \\
0,8 & 0,0030 & 0,713 & 105 \\
0,9 & 0,00067 & 0,821 & 104 \\
Среднее & & & 105 \\
\hline
\end{tabular}

-105 кДж/моль. В работе [6] на основании данных по шести экспериментальным точкам сплав также был идентифицирован как регулярный с энергией смешения $(-88 \pm 26)$ кДж/моль при температуре 1873 К, что соответствует средней величине -102 кДж/моль при температуре $2173 \mathrm{~K}$.
Bblводы. Расчет по модели идеальных ассоциированных растворов термодинамической активности компонентов бинарной металлической системы А-B, содержащей интерметаллидные химические соединения типа $\mathrm{A}_{m} \mathrm{~B}$ или $\mathrm{AB}_{l}$, где $m, l=1,2,3$, можно с приемлемой точностью выполнять, полагая, что химический состав и термодинамические свойства ассоциатов такие же, как у интерметаллидов.

\section{БИБЛИОГРАФИЧЕСКИЙ СПИСОК}

1. Пригожин И., Де фей Р. Химическая термодинамика / Пер. с англ. - Новосибирск: СО Наука, 1966. - 512 с.

2. Т рус о в Б.Г. База данных и программный комплекс Terra 2.9 - М.: МГТУ им. Н.Э. Баумана, 2006.

3. Бердников В.И., Гудим Ю.А., Картелёва М.И. // Изв. вуз. Черная металлургия. 2010. № 12. С. 3 - 6.

4. Баталин Г.И., Белобородова Е.А., Казими р о в В.П. Термодинамика и строение жидких сплавов на основе алюминия. - М.: Металлургия, 1983. - 159 с.

5. Бердников В.И., Гудим Ю.А., Картелёва М.И. // Изв. вуз. Черная металлургия. 2008. № 10. С. 3 - 6.

6. Алп атов А.В., Паде ри н С.Н. Расчет параметров взаимодействия через энергию смешения. http://steelcast.ru/interaction coefficients_calculation_02, 2011.

(С) 2013 г. В.И. Бердников, Ю.А. Гудим Поступила 11 февраля 2013 г.

УДК 669.168

\author{
Т.Б. Тойманкулов ${ }^{1}$ А.А. Акбердин ${ }^{2}$, А.К. Торговец ${ }^{1}$ \\ ${ }^{1}$ РГП «Карагандинский государственный индустриальный университет» \\ ${ }^{2}$ Химико-металлургический институт им. Ж. Абишева

\section{МАТЕМАТИЧЕСКОЕ ОПИСАНИЕ ДИАГРАММЫ ФАЗОВОГО СОСТАВА СИСТЕМЫ Fе-Mn-B}

\begin{abstract}
Аннотация. В работе с использованием принципов минимизации свободной энергии Гиббса построена диаграмма фазового состава системы $\mathrm{Fe}-\mathrm{Mn}-\mathrm{B}$ и дано ее математическое описание. Приведены примеры использования модели для оценки вида и количества примесей в металлическом марганце, железе и чистом боре.
\end{abstract}

Ключевые слова: диаграмма, балансовый метод расчета, фазовый состав.

\title{
THE MATHEMATICAL DESCRIPTION OF THE PHASE DIAGRAM IS CONSTRUCTED OF Fe-Mn-B
}

\begin{abstract}
In this paper, using the principles of minimization of the Gibbs free energy of the phase diagram is constructed of Fe-Mn-B, and given its mathematical description. Examples of using the model to assess the type and amount of impurities in manganese alloys, metallic manganese, iron and pure boron.
\end{abstract}

Keywords: chart, balance calculation method, the phase composition.

В последние годы проявлен значительный интерес к такому легирующему элементу как бор, позволяющему при низких концентрациях $(0,001-0,003)$ заметно улучшать эксплуатационные характеристики сталей. Вводят его в металл обычно в виде ферробора, получаемого дорогим алюминотермическим методом. Раз- работан и успешно опробован сравнительно простой способ получения борсодержащего ферросплава внепечным способом присадкой на струю выпускаемого из печи металла боратовых флюсов [1]. Способ отличается тем, что не требует капитальных затрат и сочетается с выпуском стандартного ферросилиция. 
В плане подготовки к организации производства ферромарганца с бором авторами выполнен ряд работ теоретического и практического плана. В настоящей работе предложена диаграмма фазового состава системы $\mathrm{Fe}-\mathrm{Mn}-\mathrm{B}$ и ее математическая модель, позволяющая оценить вид и количество образующихся в ней вторичных фаз. Последнее необходимо для подбора условий эффективного использования легирующего элемента в сталеварении.

Выполнена триангуляция изучаемой системы. В соответствии с общепринятыми процедурами, вначале на треугольник составов (см. рисунок) нанесли имеющиеся в этой системе соединения. Таковыми в бинарной системе $\mathrm{Fe}-\mathrm{B}$ являются: $\mathrm{Fe}_{2} \mathrm{~B}, \mathrm{FeB}$; в системе $\mathrm{Mn}-\mathrm{B}: \mathrm{Mn}_{4} \mathrm{~B}, \mathrm{Mn}_{2} \mathrm{~B}, \mathrm{MnB}, \mathrm{Mn}_{3} \mathrm{~B}_{4}, \mathrm{MnB}_{2}$. В системе $\mathrm{Fe}-\mathrm{Mn}$ соединений не имеется, так как между железом и марганцем образуется бесконечный ряд твердых растворов. По имеющимся литературным данным тройных соединений в этой системе не обнаружено.

Триангуляция разбивает систему $\mathrm{Fe}-\mathrm{Mn}-\mathrm{B}$ на элементарные треугольники сосуществующих фаз и сводится к оценке возможности протекания реакции взаимодействия между ближайшими соединениями по принципу минимизации энергии Гиббса [2]. Расчеты провели с использованием программного комплекса Оутокумпу. При отсутствии в базе данных требуемых термодинамических величин, они были рассчитаны по предлагаемым в работах $[3,4]$ моделям. Использованные исходные данные приведены в табл. 1. По результатам расчетов (табл. 2) продукты каждой реакции соединили прямой линией как сосуществующие, что и является предметом триангуляции.

Полученная таким образом диаграмма системы $\mathrm{Fe}-$ $\mathrm{Mn}-\mathrm{B}$ в элементарных треугольниках сосуществующих фаз показана на рисунке. В ней восемь следующих эле-

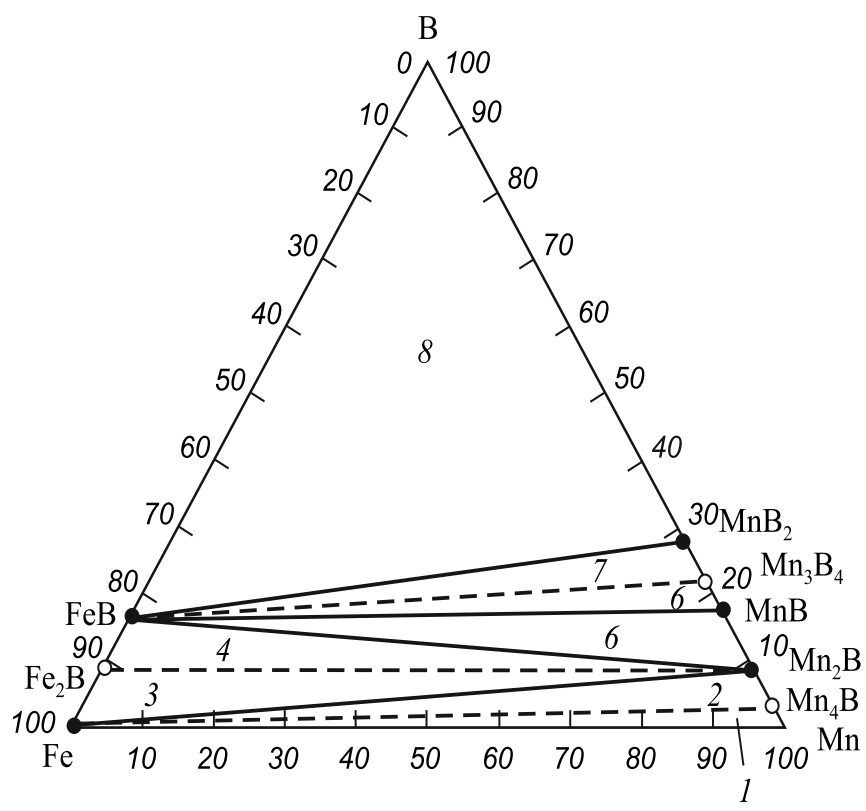

Диаграмма фазового состава системы Fe-Mn-B
Таблиц а 1

Исходные термодинамические данные

\begin{tabular}{c|c|c|c}
\hline Фаза & $\begin{array}{c}\Delta_{f} H^{0}{ }_{298,15}, \\
\text { Дж/моль }\end{array}$ & $\begin{array}{c}\Delta S_{298,15}^{0}, \\
\text { Дж/(моль } \cdot \mathrm{K})\end{array}$ & $\begin{array}{c}\Delta_{f} G^{0}{ }_{298,15}, \\
\text { Дж/моль }\end{array}$ \\
\hline $\mathrm{Fe}$ (тв.) & 0 & 0 & 0 \\
\hline $\mathrm{Mn}$ (тв.) & 0 & 0 & 0 \\
\hline $\mathrm{B}$ (тв.) & 0 & 0 & 0 \\
\hline $\mathrm{FeB}$ & -72500 & $-2,101$ & -71874 \\
\hline $\mathrm{Fe}_{2} \mathrm{~B}$ & -102510 & $-8,82$ & -99878 \\
\hline $\mathrm{Mn}_{2} \mathrm{~B}$ & -91630 & $-3,898$ & -90467 \\
\hline $\mathrm{MnB}^{\mathrm{MnB}}$ & -75312 & $-5,694$ & -73614 \\
\hline & -94140 & $-9,5$ & -91307 \\
\hline
\end{tabular}

Т а блиц и 2

\section{Значения изменения энергии Гиббса и логарифм констант равновесия реакций в системе $\mathrm{Fe}-\mathrm{Mn}-\mathrm{B}$}

\begin{tabular}{c|c|c|}
\hline Уравнение реакции & $\begin{array}{l}\Delta G^{0}{ }_{298,15}, \\
\text { Дж/моль }\end{array}$ & $\ln K_{p}$ \\
\hline $\mathrm{FeB}+2 \mathrm{Mn}=\mathrm{Fe}+\mathrm{Mn}_{2} \mathrm{~B}$ & -18593 & 7,504 \\
\hline $\mathrm{Fe}+\mathrm{MnB}=\mathrm{Mn}_{2} \mathrm{~B}+\mathrm{FeB}$ & -15113 & 6,099 \\
\hline $\mathrm{Fe}+\mathrm{MnB}_{2}=\mathrm{FeB}+\mathrm{MnB}$ & -54181 & 21,868 \\
\hline
\end{tabular}

ментарных систем: $\mathrm{Fe}-\mathrm{Mn}_{4} \mathrm{~B}-\mathrm{Mn}, \mathrm{Fe}-\mathrm{Mn}_{4} \mathrm{~B}-\mathrm{Mn}_{2} \mathrm{~B}$, $\mathrm{Fe}-\mathrm{Fe}_{2} \mathrm{~B}-\mathrm{Mn}_{2} \mathrm{~B}, \mathrm{Mn}_{2} \mathrm{~B}-\mathrm{FeB}-\mathrm{Fe}_{2} \mathrm{~B}, \mathrm{FeB}-\mathrm{MnB}-\mathrm{Mn}_{2} \mathrm{~B}$, $\mathrm{FeB}-\mathrm{Mn}_{3} \mathrm{~B}_{4}-\mathrm{MnB}, \mathrm{FeB}-\mathrm{Mn}_{3} \mathrm{~B}_{4}-\mathrm{MnB}_{2}, \mathrm{FeB}-\mathrm{MnB}_{2}-\mathrm{Mn}$.

Триангуляции выявила в системе $\mathrm{Fe}-\mathrm{Mn}-\mathrm{B}$ пять термодинамическиустойчивых областей: $\mathrm{Fe}-\mathrm{Mn}-\mathrm{Mn}_{2} \mathrm{~B}$, $\mathrm{Fe}-\mathrm{Mn}_{2} \mathrm{~B}-\mathrm{FeB}, \mathrm{Mn}_{2} \mathrm{~B}-\mathrm{FeB}-\mathrm{MnB}, \mathrm{FeB}-\mathrm{MnB}-\mathrm{MnB}_{2}$, $\mathrm{FeB}-\mathrm{MnB}_{2}-\mathrm{B}$.

При учете инконгруэнтно плавящихся соединений $\left(\mathrm{Mn}_{4} \mathrm{~B}, \mathrm{Fe}_{2} \mathrm{~B}\right.$ и $\left.\mathrm{Mn}_{3} \mathrm{~B}_{4}\right)$ система разбивается на восемь элементарных треугольников сосуществующих фаз.

Математическая модель полученной диаграммы создана на основе использовав балансового метода [5], суть которого сводится к написанию баланса распределения исходных компонентов сплава (Fe, Mn и B) между образующимися фазами. Полученные для восьми треугольников уравнения следующие:

1. $\mathrm{Fe}=\mathrm{Fe}, \mathrm{Mn}_{4} \mathrm{~B}=21,008 \mathrm{~B}, \mathrm{Mn}=\mathrm{Mn}-20,008 \mathrm{~B}$;

2. $\mathrm{Fe}=\mathrm{Fe}, \mathrm{Mn}_{4} \mathrm{~B}=2,100 \mathrm{Mn}-21,200 \mathrm{~B}, \mathrm{Mn}_{2} \mathrm{~B}=$ $=22,200 \mathrm{~B}-1,100 \mathrm{Mn}$;

$3 . \mathrm{Fe}=\mathrm{Fe}-10,186 \mathrm{~B}+1,020 \mathrm{Mn}, \mathrm{Fe}_{2} \mathrm{~B}=11,186 \mathrm{~B}-$ $-1,120 \mathrm{Mn}, \mathrm{Mn}_{2} \mathrm{~B}=1,100 \mathrm{Mn}$;

4. $\mathrm{Mn}_{2} \mathrm{~B}=1,1 \mathrm{Mn}, \mathrm{FeB}=12,200 \mathrm{~B}-1,200 \mathrm{Fe}-1,220 \mathrm{Mn}$, $\mathrm{Fe}_{2} \mathrm{~B}=1,100 \mathrm{Mn}+2,200 \mathrm{Fe}-11,100 \mathrm{~B}$;

5. $\mathrm{FeB}=1,200 \mathrm{Fe}, \mathrm{MnB}=12,000 \mathrm{~B}-1,200 \mathrm{Mn}-$ $-2,350 \mathrm{Fe}, \mathrm{Mn}_{2} \mathrm{~B}=2,150 \mathrm{Fe}+2,200 \mathrm{Mn}-11,000 \mathrm{~B}$;

6. $\mathrm{FeB}=1,200 \mathrm{Fe}, \mathrm{Mn}_{3} \mathrm{~B}_{4}=19,000 \mathrm{~B}-3,700 \mathrm{Fe}-$ $-3,800 \mathrm{Mn}, \mathrm{MnB}=3,600 \mathrm{Fe}+4,900 \mathrm{Mn}-18,000 \mathrm{~B}$; 
Химический и фазовый состав сплавов

\begin{tabular}{c|c|c|c|c|c|c}
\hline \multirow{2}{*}{$\begin{array}{c}\text { Номер } \\
\text { сплава }\end{array}$} & \multicolumn{5}{|c}{ Состав, $\%$} \\
\cline { 2 - 7 } & $\mathrm{Fe}$ & $\mathrm{Mn}$ & $\mathrm{B}$ & $\mathrm{Fe}$ & $\mathrm{Fe}_{2} \mathrm{~B}$ & $\mathrm{Mn}_{2} \mathrm{~B}$ \\
\hline & 99,99995 & $1 \cdot 10^{-5}$ & $4 \cdot 10^{-5}$ & 99,99955276 & $4,3624 \cdot 10^{-4}$ & $1,1 \cdot 10^{-5}$ \\
\hline & $\mathrm{Fe}$ & $\mathrm{Mn}$ & $\mathrm{B}$ & $\mathrm{Fe}$ & $\mathrm{Mn}$ & $\mathrm{Mn}_{4} \mathrm{~B}$ \\
\hline 2 & $3 \cdot 10^{-2}$ & 99,995 & $2 \cdot 10^{-2}$ & $3 \cdot 10^{-2}$ & 99,954984 & $4,2016 \cdot 10^{-2}$ \\
\hline & $\mathrm{Fe}$ & $\mathrm{Mn}$ & $\mathrm{B}$ & $\mathrm{FeB}$ & $\mathrm{MnB}_{2}$ & $\mathrm{~B}$ \\
\hline 3 & 0,5 & 0,2 & 99,3 & 0,597 & 0,2788 & 99,1242 \\
\hline
\end{tabular}

7. $\mathrm{FeB}=1,196 \mathrm{Fe}, \mathrm{Mn}_{3} \mathrm{~B}_{4}=1,867 \mathrm{Fe}+3,810 \mathrm{Mn}-$ $-9,524 \mathrm{~B}, \mathrm{MnB}_{2}=10,526 \mathrm{~B}-2,063 \mathrm{Fe}-2,811 \mathrm{Mn}$;

8 . $\mathrm{FeB}=1,194 \mathrm{Fe}, \mathrm{MnB}_{2}=1,394 \mathrm{Mn}, \mathrm{B}=\mathrm{B}-0,194 \mathrm{Fe}-$ $-0,394 \mathrm{Mn}$.

По приведенным уравнениям создана компьютерная программа. Она позволяет по известному химическому составу сплава рассчитать фазовый. Примеры расчетов показаны в табл. 3. Сплав № 1 представляет собой металлическое железо, где в качестве примесей находятся марганец и бор. Расчет показывает, что основу сплава действительно составляет железо, а бор и марганец находятся в нем в виде с боридов железа $\left(\mathrm{Fe}_{2} \mathrm{~B}\right)$ и марганца $\left(\mathrm{Mn}_{2} \mathrm{~B}\right)$. Аналогичным образом выполнен расчет фазового состава металлического марганца (№ 2) и чистого бора (№ 3). Знание форм присутствия примесей позволяет облегчить подбор способов очистки металла с сохранением его основы.

Выводы. Построена диаграмма фазового состава системы Fe-Mn-B, дано ее математическое описание, создана компьютерная программа для численных расчетов. Она может быть использована для оценки фазового состава ферросплавов, чистоты марганца, железа и бора по примесным элементам. Приведены примеры таких расчетов. Предварительная оценка фазового состава сплавов позволит подобрать эффективные способы их рафинирования от примесей и применения в сталеварении.

\section{БИБЛИОГРАФИЧЕСКИЙ СПИСОК}

1. Жучков В.И., Акбердин А.А., Леонтьев Л.И. и др. Производство и использование новых борсодержащих ферросплавов в черной металлургии: Тр. науч.-техн. конф. «Проблемы и перспективы развития металлургии и машиностроения с использованием завершенных фундаментальных исследований и НИОКР». - Екатеринбург: УрО РАН, 2011.С. 198 - 201.

2. Процюк А.П., Карап е тья н М.X. // Журнал прикладной химии. 1977. № 1. С. $169-171$.

3. Методы прикладной термодинамики в химии и металлургии / Б.К. Касенов, М.К. Алдабергенов, А.С. Пашинкин и др. - Караганда: Глассир, 2008. - 332 с.

4. Мораче в ски й А.Г., Сладков И.Б. Термодинамические расчеты в металлургии: Справочник. - М.: Металлургия, 1985. $-136 \mathrm{c}$.

5. А кберд и н А.А. // Комплексное использование минерального сырья. 1995. № 3. С.92 - 93.

(C) 2013 г. Т.Б. Тойманкулов, А.А. Акбердин, А.К. Торговеи Поступила 15 марта 2013 г. 